Research Journal of Poultry Sciences 5 (1): 4-8, 2012

ISSN: $1993-5285$

(C) Medwell Journals, 2012

\title{
Pathogenecity Trial of IBV in Diffferent Route of Inoculation in Embryonated Chichken Eggs
}

\author{
${ }^{1} \mathrm{~K}$. Devaki, ${ }^{1}$ Roshmi Mohan Kanchana and ${ }^{2} \mathrm{R}$. Narmadha \\ ${ }^{1}$ Department of Biochemistry, Karpagam University, 641021 Coimbatore, Tamil Nadu, India \\ ${ }^{2}$ Harsha Aqua Firm, 641028 Coimbatore,Tamil Nadu, India
}

\begin{abstract}
Infectious Bronchitis Virus (IBV) which causes infectious bronchitis in poultry industry produces extensive economic loss to any poultry operation. Obvious failures in various vaccination programs necessitate the new vaccine development. Virus cultivation is the first step in vaccine production so, this study aimed in finding the best route of inoculation for virus cultivation in embryonated chicken eggs. The 5 and 9 days old embryonated chicken eggs were used and the inoculation of IBV is done in three routes namely yolk sac, chorio allantoic fluid and chorio allatoic membrane and the lesions were observed. More prominent observations like stunting embryo, Cashew nut appearance and expulsion of internal organs confirms that yolk sac route is the best route for cultivation of IBV.
\end{abstract}

$\underline{\text { Key words: Virus cultivation, IBV, chick embryo, viral assay, inoculation, vaccination }}$

\section{INTRODUCTION}

In the new era, poultry rearing is one of the well flourishing industries. It has a high commercial value since, it is used for the production of eggs, meat and egg proteins. Several pathogens can pass through the eggs from infected hens to offspring causing heavy mortalities in chickens. One such pathogen is Infectious Bronchitis Virus (IBV) which is devastating to any poultry operation. It affects the chickens of all ages, types and breeds. The disease is caused by coronavirus which is known to have a high mutation rate (Ambali and Jones, 1990). Egg production and egg quality problems were first attributed to the same virus in 1951 and syndrome of kidney damage in 1962. Infectious bronchitis associated problems continue to be reported from all countries with a developed chicken industry. The economic losses of this disease are due to mortality, morbidity, drop in egg production, delayed sexual maturity, abnormal shell and internal egg quality, poor FCR (Feed Conversion Ratio), increased number of non layers, retarded growth rate, reduced fertility and hatchability (Crinion, 1972; Muneer et al., 1986; McMartin, 1968). A control program for this disease is through biosecurity and vaccination. Live attenuated $\mathrm{BV}$ vaccine introduced as vaccine in 1950 followed a couple of decades later by inactivated vaccines for boosting protection in egg laying birds. Obvious failures from various vaccination have been documented and they underscore the urgent need for the development of other vaccines. Embryonated eggs are suitable medium for the growth of viruses providing an important mean of obtaining large quantities of viruses for the preparation of vaccines and diagnostic reagents as well as for viral studies because of its unlimited availability, easy handling providing controlled environment for viral growth, inability to produce antibodies against viruses and also availability of uniform genetic constituents.

Several portions of the embryonated eggs are used for viral cultivation including the allantoic and amniotic cavities, yolk sac, chorio allantoic membrane and embryo itself. The particular region used depends on the virus to be cultured as certain viral agents are capable of proliferating only in some parts of the embryo. The viral infection in chick embryo appears in several ways, certain viral agents produce local lesion called pocks that vary in size, shape and opacity. Additional macroscopic signs include stunted embryo, deformed organs and even death of embryo (Presscott et al., 1996; Wistreich, 1986).

The present study aimed in finding the best route of inoculation for cultivating the virus using embryonated chicken eggs. The routes used for the present study are:

- Yolk sac

- Chorio allantoic cavity

- $\mathrm{CAM}$ (Chorio Allantoic Membrane route)

\section{MATERIALS AND METHODS}

Glasswares used were of good quality viz. Borosil/ Corning (with neutral $\mathrm{pH}$ ) and plastic ware were of special type of plastic viz., polypropylene (pp), mainly to withstand autoclaving temparature of $121^{\circ} \mathrm{C}$ for $15 \mathrm{~min}$.

Corresponding Author: K. Devaki, Department of Biochemistry, Karpagam University, 21 Coimbatore, Tamil Nadu, India 


\section{Biological products}

Embryonating Chicken Eggs (ECE): The 5 and 9 days old embryonating chicken eggs were procured from a private hatchery locally for testing the seed material viz., chicken embryo adapted IBV H 120 strain.

IBV H 120 (egg adapted) vaccine: Egg adapted B BV H 120 vaccine was obtained from Institute of Veterinary Preventive Medicine (IVPM), Ranipet. The vaccine was stored in freezer till use.

\section{Solution}

Normal Saline (NS): About $500 \mathrm{~mL}$ of sodium chloride $(0.85 \%)$ solution was prepared using triple distilled water. The $\mathrm{pH}$ of the solution was adjusted between 7.2 and 7.4 and it was divided into required aliquots, sterilized at $121^{\circ} \mathrm{C}$ for $15 \mathrm{~min}$ cooled to room temperature and preserved at $4^{\circ} \mathrm{C}$ mainly to serve as diluents during virus titration.

Antibiotics: About 200 International Unit (IU mL ${ }^{-1}$ ) of ampicillin, $200 \mathrm{mg} \mathrm{mL}^{-1}$ of streptomycin sulphate was used for egg inoculations for preventing the bacterial growth.

\section{Equipments}

Egg driller: Engerotool was purchased from Namakkal surgicals, Tamil Nadu. It was used for the purpose of making pinpoint hole on the egg shell.

Candling box: Candling box was procured locally and used for candling the embryonating chicken eggs so, as to confirm the age of the embryos at every stage of the trial.

\section{GLASSWARE AND PLASTICWARE}

Tuberculin syringe: Twenty two G hypodermic needle about one and a half length along with $2 \mathrm{~mL}$ capacity to tuberculin syringe, enabling the change of needle is highly preferred. The syringe consists of subdivisions of $1 \mathrm{~mL}(0.1-0.2 \mathrm{~mL})$ facilitating $0.2 \mathrm{~mL}$ quantity of viral inoculam to be exactly delivered into three routes.

Disposable tips: Disposable tips were used for handling the samples in all experimental procedures.

Common glassware: Conical flasks, pipettes and beakers of different capacities, petri dishes, funnels etc., were procured for various steps involved in egg inoculation.
Paraffin wax (hard paraffin) or cello tape: Wax is melted and allowed to cool a bit and before solidification, few drops of it is used which is sufficient to seal the hole. Incase of cello tape, two strips of about $2 \mathrm{~cm}$ are placed on the hole as +mark.

Preparation of glassware and plastic ware: All the glassware and plastic ware were soaked in liquid soap solution with neutral $\mathrm{pH}$ overnight (Labolein, Qualigens). The soaked materials were washed thoroughly with running tap water. Subsequently the washed items were transferred to distilled water and rinsed thrice on 3 consecutive days. The thoroughly dried items were packed using double layer of news paper, autoclaved at $121^{\circ} \mathrm{C}$ for $15 \mathrm{~min}$. The sterile items thus, prepared were carefully placed in a clean cabinet instrument, until further use.

\section{Potency confirmation of the seed material-egg adapted IBVH 120}

Preparation of eggs for virus inoculation: For different route of inoculation twenty actively moving 5 and 9 days old chicken embryos were selected. The border of the air sac and the position of the embryo were marked during candling. The earliest candling is conducted at 5th day of incubation mainly required for yolk sac route of inoculation. At this early stage, fertility is confirmed by the presence of an eyespot.

Eggs, one by one are placed on the hole of the candling box meant specially for placing eggs for which source of light pass from bottom. Powerful bulbs must be avoided while candling, to prevent the eggs from heated up quickly and hence $15-25 \mathrm{~W}$ is sufficient. Position of the embryo is marked with the help of eyespot as its position is almost fixed and quiet prominent mainly because of its darker nature.

Drilling of eggs: Drilling was carried out just before inoculation. The surface of the egg was sterilized with $70 \%$ alcohol. In case of allantoic route using an electrically operated egg driller a pinpoint hole was drilled at a distance of about $2 \mathrm{~mm}$ above the border of the air sac, opposite to the position of the embryo taking care not to pierce the underlying membrane. In case of yolk sac route one pinpoint was drilled at the center of the air sac. Two holes were made in the case of CAM route of inoculation. One pinpoint hole was made on the air sac and a linear hole was made on the side of the cell membrane (at a blood vessel free area opposite to the position of embryo).

Preparation of inoculum: Chicken embryo adapted IBV (1000 doses) freeze dried powder was reconstituted in 
$1 \mathrm{~mL}$ of normal saline and mixed with antibiotics namely ampicillin (200 $\Pi \mathrm{mL}^{-1}$ ) and streptomycins (200 $\mathrm{mg} \mathrm{mL}^{-1}$ ). The antibiotic treated egg adapted BV was mixed well and incubated at $37^{\circ} \mathrm{C}$ for $20 \mathrm{~min}$ enabling the antibiotics to act upon the inoculum.

Chorio allantoic inoculation and subsequent sealing of the hole: A hypodermic needle of about $4-4.5 \mathrm{~cm}$ long attached to a $2 \mathrm{~mL}$ tuberculin syringe (glass) with $0.1 \mathrm{~mL}$ marking was used for inoculating the virus suspension. About $0.2 \mathrm{~mL}$ of inoculam was inoculated into the chorio allantoic cavity by inserting the needle at a $45^{\circ}$ angle to the curvature of the egg. Simultaneously two more eggs were left uninoculated so, as to serve as uninoculated controls. Using molten hard paraffin wax, the inoculated hole was sealed. The inoculated eggs were continued incubation at $37^{\circ} \mathrm{C}$ for $18-36 \mathrm{~h}$.

CAM route inoculation and subsequent sealing of the hole: About $0.2 \mathrm{~mL}$ of the inoculum was inoculated drop by drop into the linear hole on the side of the shell membrane without piercing the shell membrane. A bulb teat or rubber bulb is evacuated of the air inside by squeezing completely and that applied tightly over pinpoint hole at the center of the air sac.

Now the rubber bulb is released slowly which sucks the air from the air sac thus marking the chorio allantoic membrane that was loosened on the curvature of the egg (linear hole region). The viral inoculum is simultaneously brought will be sucked inside successfully. Using molten paraffin wax, the inoculated hole was sealed. The inoculated eggs were continued incubation at $37^{\circ} \mathrm{C}$ for 18-36 h.

Yolk sac inoculation and subsequent sealing of the hole: About $0.2 \mathrm{~mL}$ of the inoculam was inoculated into the yolk sac cavity by inserting the needle just perpendicular to the surface of the egg. Using molten paraffin wax, the inoculated hole was sealed. The inoculated eggs were continued incubation at $37^{\circ} \mathrm{C}$ for $36 \mathrm{~h}$.

Further processing and harvesting of inoculated eggs: All the above twenty inoculated eggs were candled; preferably $12 \mathrm{~h}$ post incubation. Those embryos which died within $24 \mathrm{~h}$ post incubation were discarded attributing to accidental injuries. Those embryo mortalities at $24-48 \mathrm{~h}$ incubation were preserved at cooler temperature $\left(4^{\circ} \mathrm{C}\right)$ overnight.

The surface sterilization of the egg shell was repeated just before the harvesting procedure. The egg shell over the air sac cut open and the egg was placed on

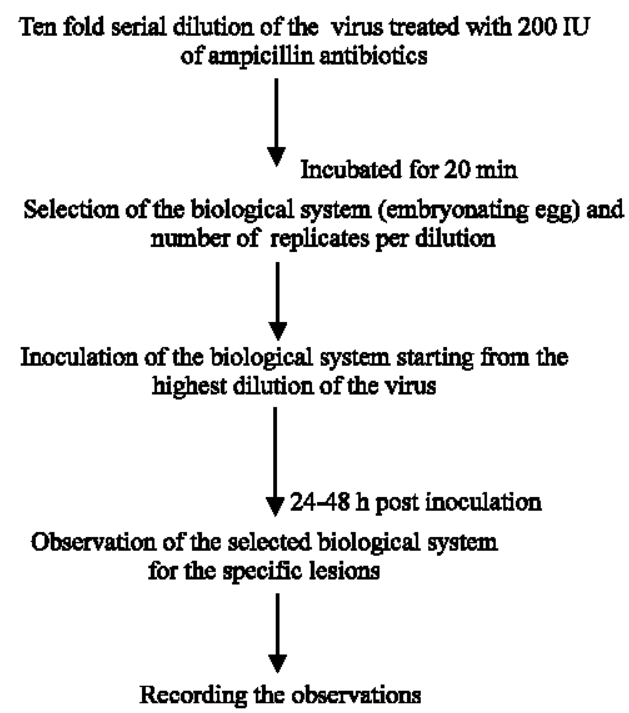

Fig. 1: Viral assay in embryonated chicken eggs

the egg holder. The underlying membrane, forming the floor of the air sac was cut open using a pair of sterile forceps. Using forceps alone, the contents of the eggs were gently passed to one side so as to harvest clear allontoic fluid using a Pasteur pipette and transferred into a sterile container. After collection of allontoic fluid completely, the embryo was collected by hooking the neck of the embryo in between the two arms of the scissors or forceps and was transferred to a petri dish to observe specific lesions. The flowchart provide viral assay in embryonated chicken eggs in Fig. 1.

\section{RESULTS AND DISCUSSION}

The results obtained from the three routes of inoculation are shown in Table 1.

Yolk sac route inoculation: In the case of yolk sac route of inoculation, the lesions observed were the stunting embryo, cashew nut appearance and expulsion of internal organs. The yolk sac appears shrunken and the membrane ruptures easily. An increased volume of clear allantoic fluid was found. Evidence of lesions usually detected on 3rd day after inoculation was also reported by Gelb et al. (1991) (Fig. 2).

Chorio allantoic route of inoculation: Characteristic embryo changes were seen 3 days after inoculation of the virus. Only slight movement of dwarfed embryo observed during candling. Upon opening the air cell end of the egg, the embryo was seen curled into spherical form with feet 

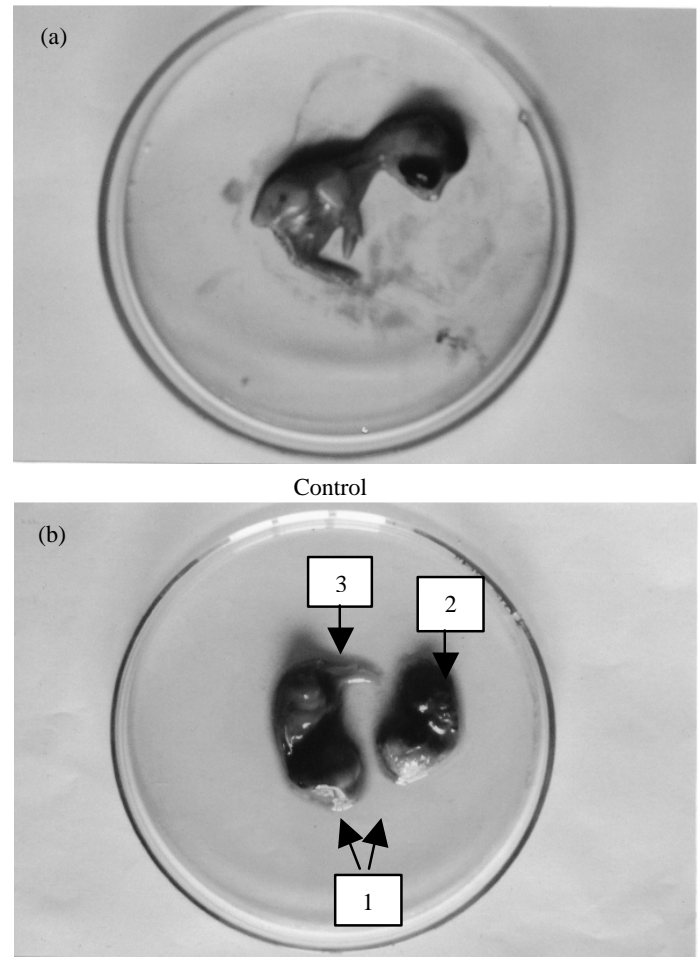

Fig. 2: Results of yolk sac route inoculation of IBV; a) Control; b) Treated; 1) Stunting of embryo; 2) Cashew nut; 3) Expellsion of internal organs

Table 1: The results of different route of inoculation of IBV in embryonated

\begin{tabular}{|c|c|c|c|}
\hline $\begin{array}{l}\text { Route of } \\
\text { inoculation }\end{array}$ & $\begin{array}{l}\text { Days of } \\
\text { inoculation }\end{array}$ & Lesions observed & $\begin{array}{l}\text { No. of days } \\
\text { of observation }\end{array}$ \\
\hline Yolk sac route & $5-7$ days & $\begin{array}{l}\text { Stunting embryo } \\
\text { Cashew nut appearance } \\
\text { Expellsion of internal } \\
\text { organs }\end{array}$ & 3 days/live \\
\hline $\begin{array}{l}\text { Chorio allantoic } \\
\text { route }\end{array}$ & 9-11 days & $\begin{array}{l}\text { Haemorrhagic embryo } \\
\text { Dwarfing } \\
\text { Curling }\end{array}$ & 3 days/live \\
\hline CAM route & 12 days & $\begin{array}{l}\text { Vesicles on CAM } \\
\text { Pock lesions on CAM }\end{array}$ & 3 days/live \\
\hline
\end{tabular}

deformed and compressed over the head and with the thickened amnion adhered to it. Hemorrhages were also seen in the chick embryo (Clarke et al., 1972) (Fig. 3).

CAM route of inoculation: The chorio allantoic membrane was useful tissue for those virus which produce lesions that is formation of pocks and the development of pocks which affords a readily demonstrable effect.

The CAM in essence provides an equivalent solid sheet of cells on which virus can grow and infective viral particle are capable of giving rise to pock. In the case of CAM route of inoculation in the study, the lesions
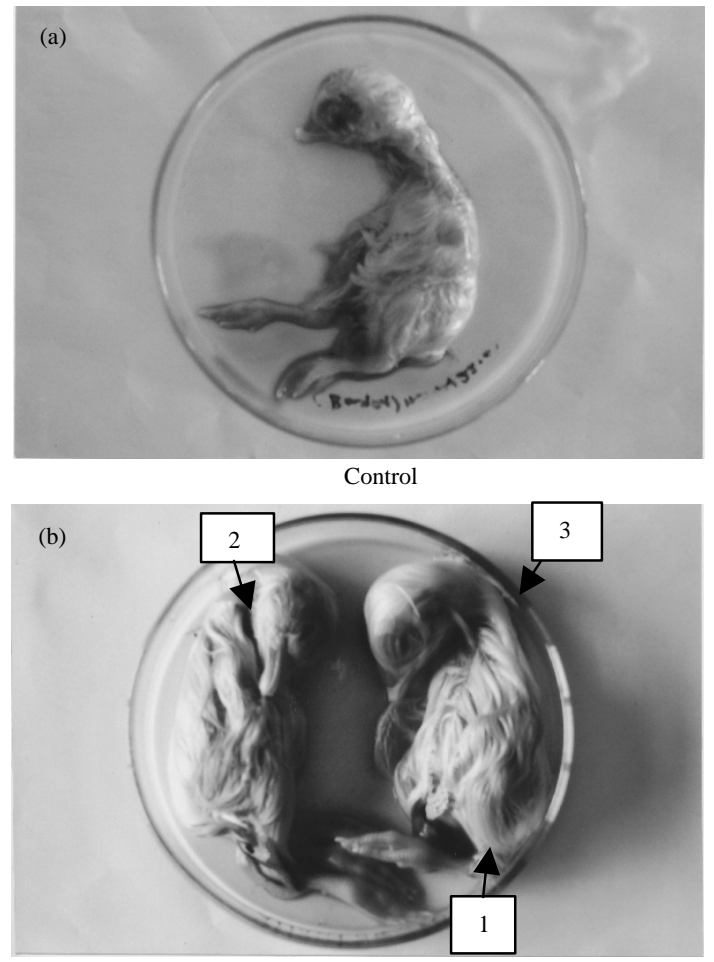

Fig. 3: Result of chorioallantoic route inoculation of IBV; a) Control; b) Treated; 1) Haemorrhigie embryo; 2) Dawarfing 3) Curling

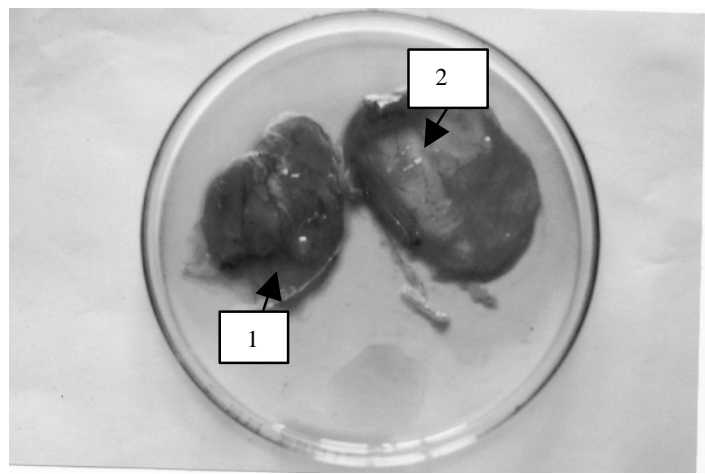

Fig. 4: Result CAM route inoculation of IBV; 1) Vesicles on CAM; 2) Pock lesions on CAM

observed were the vesicles on the chorio allantoic membrane and the pock lesions on CAM bring the transparent result (Loomis et al., 1950) (Fig. 4).

\section{CONCLUSION}

The results from the study confirms that the yolk sac route is the best route for the cultivation of IBV virus since, it produce more prominent lesions. 


\section{ACKNOWLEDGEMENT}

The researchers are grateful to Karpagam University for providing required assistance in completing the project.

\section{REFERENCES}

Ambali, A.G and R.C. Jones, 1990. Early pathogenesis in chicks of infection with an enterotropic strain of infectious bronchitis virus. Avian Dis., 34: 809-817.

Clarke, J.K., J.B. McFerran and F.W. Gay, 1972. Use of allantoic cells for the detection of avian infectious bronchitis virus. Arch. Virol., 36: 62-70.

Crinion, R.A.P., 1972. Egg quality and production following infectious bronchitis virus exposure at one day old. Poult. Sci., 51: 582-585.
Gelb, J., J.B. Wolff and C.A. Moran, 1991. Variant serotypes of infectious bronchitis virus isolated from commercial layer and broiler chickens. Avian Dis., 35: 82-87.

Loomis, L.N., C.H. Cunningham, M.L. Gray and F. Thorp, 1950. Patyhology of chicken embryo infected with infectious bronchitis virus. Avian Dis., 9: 308-316.

McMartin, D.A., 1968. The pathogenecity of an infectious bronchitis virus for laying hens. Br. Vet. J., 124: 576-581.

Muneer, M.A., D.A. Halvarson, V. Sivanandan, I.A. Newman and C.N. Coon, 1986. Effects of infectious bronchitis virus (Arkansas strain) on laying chickens. Avian Dis., 30: 644-647.

Presscott, L.M., J. Harley and D.A. Klein, 1996. Microbiology. 3rdEdn., McGraw Hill Company, USA.

Wistreich, L., 1986. Microbiology. 3rd Edn., Glencoe Publishers, USA. 